\title{
Quo Vadis, Macromolecular Science? Reflections by the IUPAC Polymer Division on the Occasion of the Staudinger Centenary
}

Volker Abetz, ${ }^{[a]}$ Chin Han Chan, ${ }^{[b]}$ Christine K. Luscombe, ${ }^{[c] *}$ John B. Matson, ${ }^{[d]}$ Jan Merna, ${ }^{[e]}$ Tamaki Nakano, ${ }^{[f]}$ Guido Raos, ${ }^{[g]}$ Gregory T. Russell ${ }^{[h] *}$

[a] Institute of Physical Chemistry, Universität Hamburg; Helmholtz-Zentrum Geesthacht, Institute of Polymer Research, Germany

${ }^{[b]}$ Faculty of Applied Sciences, Universiti Teknologi MARA, 40450 Shah Alam, Selangor, Malaysia

[c]* Materials Science and Engineering Department; Molecular Engineering and Sciences Institute, University of Washington, Seattle, USA; E-mail: luscombe@uw.edu; Tel: +1-206-616-1220; Fax: $+1-206-221-4934$

[d] Department of Chemistry, Virginia Tech Center for Drug Discovery, and Macromolecules Innovation Institute, Virginia Tech, USA

${ }^{[e]}$ Department of Polymers, University of Chemistry and Technology, Prague, Czech Republic

${ }^{[f]}$ Institute for Catalysis, Division of Biotechnology and Macromolecular Chemistry, Faculty of Engineering, Hokkaido University, Japan

${ }^{[h]}$ Dipartimento di Chimica, Materiali e Ing. Chimica “G. Natta”, Politecnico di Milano, Italy

[i]* School of Physical and Chemical Sciences, University of Canterbury, Private Bag 4800, Christchurch, New Zealand; E-mail: greg.russell@canterbury.ac.nz; Tel: +64-3-3695129; Fax: $+64-3-3642110$

Published on Isr. J. Chem. (2020):

https://onlinelibrary.wiley.com/doi/full/10.1002/ijch.201900182 


\title{
Keywords
}

History of science; macromolecules; materials science; polymers; Staudinger.

\begin{abstract}
We survey the past, present and future of polymers and macromolecular science, both in general and giving specific examples from our diverse array of research backgrounds within polymer science and technology. As befitting our common bond, we pay some attention to the role of IUPAC. In line with this being part of a Rosarium philosophorum, one might say we conclude that it is Citius, Altius, Fortius for polymers in the century ahead, by which we mean "faster engagement, higher value, stronger properties", and one should also add "longer usage”. In this way our broad community will continue to build on the century that has passed since Hermann Staudinger launched macromolecular science.
\end{abstract}

\section{Introduction}

If it's a bad time to be a chemist, then it's an even worse time to be a polymer chemist: at some level we've always been blamed for pollution, but the jeers regarding supermarket bags and plastics in the oceans have become deafening in recent times. At least we aren't blamed for global warming, but with the way that social media fans superstition in the public, this may well be coming (notwithstanding that "capture" of carbon in synthetic polymers actually plays a role in reducing the eventual amount of $\mathrm{CO}_{2}$ reaching the atmosphere from oil exploitation). As we celebrate the centenary of Staudinger's "macromolecular concept" ${ }^{[1]}$ we can feel relieved that the word "macromolecule" is not yet reviled by the public, notwithstanding that Staudinger actually 
didn’t coin this word until 1922, as detailed in the long overdue English translation of his 1920 paper that has just been published by Frey and Johann. ${ }^{[2]}$

What we are dealing with here is our own specific manifestation of the general phenomenon that the cognitive psychologist (and polymath) Stephen Pinker has recently addressed in his book Enlightenment Now: "Newborns who will live more than eight decades, markets overflowing with food, clean water that appears with a flick of a finger and waste that disappears with another, pills that erase a painful infection, the world's knowledge and culture available in a shirt pocket ... The great successes the world has enjoyed over the past decades and centuries are taken for granted ... Announce that the world has gone badly wrong, that there are too many people, the Earth has been despoiled, we've never been in greater danger of death and destruction ... and you'll have the nodding attention of the news media and the intellectual classes."[3] Yes, Staudinger came well after the Age of Enlightenment, but it is clear that he and we are still riding that wave, because polymers are involved in all of the advances listed here. The Staudinger centenary should be seized as an opportunity to remind the public that a life without polymers would be one of unimaginably and unbearably lower quality, even if there has been some pain with all the massive gains. We in IUPAC hereby take this opportunity!

As far as we are aware it is purely by chance that IUPAC and "macromolecules" were born so close together, in 1919 and 1920 respectively. Nevertheless, this coincidence does seem to intertwine the two, as reflected by IUPAC's centenary now ending exactly as Staudinger's commences. In fact it was not until 1967, nearly 50 years after IUPAC and macromolecular science came into existence, that IUPAC's "Macromolecular Division" followed suit. ${ }^{[4]}$ Another coincidence: 1967 also witnessed Hollywood's most famous nod to our field, with the immortal “One word: plastics” scene in The Graduate. Since 2004 we have been known as the "Polymer 
Division”, our overall goal being to promote the science and technology of macromolecules and polymers - yes, there is a difference! ${ }^{[5]}$ - at the international level by facilitating international scientific exchanges, by cooperating with international organizations for activities such as education and conferences, and by defining terminology and standards related to macromolecules and polymers. ${ }^{[6]}$ With this article we contribute towards that mission.

Where elsewhere an individual IUPAC account prompted by Staudinger’s centenary has recently been published, ${ }^{[7]}$ here in true IUPAC fashion there is a diverse authorship team spanning 4 continents, 7 countries and too many research specialties to enumerate. This team arose from the Polymer Division not by design but through self-assembly, which is appropriate given that this is such a common motif in modern macromolecular science! Our intent is to provide our collective viewpoint that reflects our diverse backgrounds, areas of expertise, and interests, rather than to promote specific areas of research. We found the provided “interview questions" to be an excellent framework for organizing and presenting our reflections, which now follow in the Discussion.

\section{Discussion}

\section{How do you view the historical development of macromolecules?}

The field of macromolecules had to form sooner or later, since macromolecules are all around us. Macromolecules played a crucial role on our planet long before they were recognized by people. We know now that natural macromolecules, including proteins, polysaccharides and polynucleotides, are the basis of and for life. Humans have used these natural macromolecules in many ways. For example, cellulose in wood and cotton has been used to build structures and create clothing, and proteins from silkworms have been made into silk for centuries. Beyond these major biomacromolecules, rubber obtained from the latex of Hevea brasiliensis has been turned into 
commercial materials for at least the past two centuries (Figure 1A). In a practical way, humans were macromolecular scientists and engineers millenia before anyone knew what a macromolecule even was, in much the same way that humans who made wine were microbiologists well before anyone had identified yeast.

Even towards the end of the 19th century (i.e., well after the Industrial Revolution but still before Staudinger's macromolecular hypothesis), when natural materials had begun to be replaced by synthetic ones, the use of macromolecules was still unconscious. For example, ivory was successfully replaced by nitrocellulose (celluloid), which later, after softening by camphor, gave rise to cellophane, a support material for photographic film. ${ }^{[8]}$ Bakelite, the first commercial thermoset, came along in the early 20th century and found its way into many products. ${ }^{[9]}$

Macromolecular design grew more rationally after Staudinger's contributions, ${ }^{[1]}$ which were paramount. In Staundinger's time, and even now to a large degree, chemists aim to synthesize, isolate and characterize a single, well-defined product. Molecular weight distributions, “errors" in tacticity or regioregularity, and other "impurities" in polymers as a result of "imperfect" polymerizations were viewed as disadvantages rather than features that could be understood and perhaps controlled. Pioneers in our field followed Staudinger; for example, Carothers developed nylon and neoprene. ${ }^{[10,11]}$ Other macromolecules were first synthesized by chance around this time, e.g. low-density polyethylene, ${ }^{[12]}$ but their polymeric nature was recognized quickly due to the knowledge of macromolecular concepts. This allowed further development of synthesis, processing conditions, and commercialization to proceed quickly. Rapid growth of the petrochemical industry in the mid-20th century played a vital role in the development of polymers in this period of time, providing inexpensive and abundant access to monomers (e.g., olefins). These synthetic macromolecules not only replaced other materials like metals, glass, and wood in 
specific applications (Figure 1B), but entirely new polymeric materials were developed because of their low cost and unique mechanical properties. It is hard to overstate the roles that Ziegler and Natta played in this time in the development of polyolefins, ${ }^{[13,14]}$ ushering in the age of plastics and strong links between the fields of chemistry, chemical engineering, materials science, and polymer science and engineering.

After Ziegler, Natta and other mid-20th century polymer chemists, sophisticated polymer materials began to be developed with unprecedented thermal and mechanical properties. Familiar examples include high modulus fibres based on aromatic polyamides, ultrahigh molecular weight polyethylene, and many polymer composite materials used in the aerospace industry (Figure 1C). Polymers now appear in an astounding number of products that we interact with or rely on every day. For example, polymeric adhesives and thermally stable polymers permeate our electronic devices; permeable yet chemically resistant polymers enable the hemodialysis and desalination of sea water by reverse or forward osmosis and the separation of industrially important gases like hydrogen, oxygen, nitrogen, methane, and $\mathrm{CO}_{2}$; degradable polymers allow surgeons to close a wound while avoiding the need to remove the sutures; and discovery of $\pi$-conjugated semiconducting polymers has created a new research area in organic electronics.

We have now reached an age where plastic production is greater than steel production (Figure 2). However, this has environmental repercussions. Somewhat ironically, after several decades of developing methods to make plastics stronger, longer-lasting, and more resistant to stress and degradation, polymer chemists now face the challenge of finding ways to allow polymers to degrade in a sustainable way. We seek to prevent polymers with intended lifetimes of weeks from persisting in the environment for centuries. This goal has led to the development of synthetic degradable polymers, such as polylactide, and a recognition that materials derived from 
natural polymers, such as cellulose, continue to hold great value as sustainable and renewable plastics. The historical development of macromolecules, from millenia ago through Staudinger's contributions to today, has shown that our field is full of exciting phenomena and materials, and this will not change in the next 100 years. All that is needed to discover them is curious, ambitious and persistent scientists. It behooves us to make sure there is a steady supply of such people.

2. What have been the most significant contributions of macromolecules to science/humankind?

The phrase "too numerous to mention" hardly does justice to this situation. Nevertheless, here follows a list of significant contributions, in no particular order and with no pretence of exhaustion; furthermore, examples are illustrated in Figure 3 in many cases:

The lightweight, low-cost and effective barrier and insulation properties of polymers make them invaluable to humankind, helping to solve major problems connected with limited sources or access to potable water, food and energy.

Use of polymers for packaging protects food and drink from contamination and decay during transport and storage, reducing food waste and preventing the spread of disease.

The insulation properties of polymers save huge amounts of energy for heating and cooling of spaces within buildings, not to mention the improvements in human health that follow from being able to live in environments that are neither too hot nor too cold.

Massive amounts of fuel are saved by the low density of polymers used in vehicle construction.

Furthermore, these plastics can absorb energy upon vehicular impact, thereby creating a "crumple zone" that protects occupants and has been hugely significant in saving lives and reducing injuries from car crashes. 
In paints and other coatings, polymers provide enormous benefit in extending the lifetime of objects and structures made from metal, wood, and brick.

Clothing based on synthetic polymers saves huge amounts of water and fertilizer that would otherwise be necessary to grow cotton or produce wool or leather.

Without polymers as insulators, the electric and electronic devices critical to civilization in the 21st century would not work.

Semiconducting polymers have made possible the development of organic LED displays and organic photovoltaic solar energy panels.

More recently, soft macromolecular materials have moved into the high-value sector of biomaterials, where the development of hydrogels ${ }^{[15]}$ has made possible soft contact lenses ${ }^{[16]}$ and hydrogel implants which improve the lives of hundreds of millions of people.

The large size of macromolecules is critical for their transport through body membranes, making them suitable as drug carriers. Precise macromolecular design and introduction of specific functionalities make it possible for macromolecules at the interface of the synthetic and natural worlds to be used for controlled and targeted drug delivery or sensors. ${ }^{[17]}$

Polymers with increased sensitivity to degradation have revolutionized medicine, giving sutures and temporary implants which do not need to be removed surgically.

Similarly, in agriculture, where polymers provide the means for controlled release of fertilizers, crop protecting agents or mulching foils.

Lastly, and as a general point, we opine that focus should not only be on the countless benefits to our daily life that synthetic macromolecules have provided, but also on what synthetic macromolecules have enabled us to learn about the world. In other words, we should count as "significant contributions" all the glorious areas of scientific learning that macromolecules have 
opened up. For example, entanglements give polymers their mechanical properties, and without polymers a whole branch of science on how entangled structures behave would be lost. This has implications in areas such as the study of DNA, which does not get tangled up. If it did, we would be in serious trouble when our cells needed to transcribe DNA!

3. How would you respond to a comment that the field encompasses service tools rather than independent science?

The science of macromolecules has never been and will never be independent from other scientific disciplines. Rather, it is an interdisciplinary science of classical disciplines like organic chemistry, inorganic chemistry, physical chemistry and physics (Figure 4). Furthermore, it benefits strongly from a large number of mathematical methods. Of course, an analogous statement holds for all other fields of chemistry and physics, with only mathematics being a pure science of itself, not requesting anything from the real universe. So, if we exclude mathematics and informatics, all natural sciences are interlinked with each other directly or indirectly, either by the matter (composed of atoms) that they deal with, or by the concepts for describing matter and relating it to its properties, or by both. Thus all disciplines can portray themselves as being at the centre of all science, and for macromolecular science this picture looks as in Figure 4. For practitioners of macromolecular science this feeling of centrality is very real, and there is certainly not the slightest sensation of being a more "service tool", far from it.

As implied by Figure 4, the different disciplines of chemistry still have their specificities making them distinct from other disciplines. While low molecular weight organic chemistry reactions lead to well defined products (neglecting isotope distributions such as those from ${ }^{12} \mathrm{C}$ and ${ }^{13} \mathrm{C}$ ), the same reactions - e.g. esterification, amidation, Diels-Alder - deployed in polymer 
chemistry result in a distribution of macromolecules. This distribution of chain lengths leads automatically to a blend or mixture of different macromolecules, even if they differ from each other only by the number of repeating units. Synthetic polymer chemistry is mainly based on organic chemistry and to a lesser extent on inorganic chemistry, while the methods of physical chemistry are used to describe the reaction kinetics and their thermodynamics, for example.

A particular difference between the physical properties of polymers from other materials like metals and ceramics is their pronounced time-dependent response to external forces. Application of a sudden stress leads to a time dependent creep, while, vice versa, a sudden strain leads to a time-dependent stress relaxation. This is very different from low molecular weight inorganic or organic solids and liquids, which respond without time delay to external forces. These so-called visco-elastic properties in combination with a large number of metastable or frozen-in states enable the fabrication of materials with different properties from a given polymer by choosing suitable processing routes. Shape memory polymers are a prominent example of this.

Therefore, besides chemical structure also macromolecular conformational order influences mechanical properties, and processing influences macroconformations. While low molecular weight materials display changing physical properties when their size is reaching the nanometer regime (e.g. confinement effects in semiconductors leading to spectroscopical shifts), physical properties in polymers depend on the state of stress, which may be even inhomogeneously distributed within the material. The increasing possibilities in computer simulation on one side and the increasing possibilities in time resolved characterization and manipulation of materials may lead to materials with new properties, if processing can be directed along the free energy landscape of the polymer following prediction of theory and simulation. ${ }^{[18]}$ 
These are just some examples of ways in which macromolecular science stands distinct from the other fields of chemistry, even if there is obviously overlap with each of them. This overlap is obviously important in terms of future developments in macromolecular science and technology, because often such developments flow from advancements in other disciplines. For example, advances in inorganic and organic chemistry often lead to new synthetic possibilities in macromolecular chemistry. But this is not something that relegates polymer chemistry to being a mere "service science", because such borrowing is common to all areas of science. For example, developments in solid-state physics result in faster computers, while medicinal chemistry has been greatly advanced by developments in quantum chemistry and computing. All areas of science are interdisciplinary, as implied by Figure 4 .

These general thoughts show that polymer science is to some extent specific and distinct from other natural sciences, but at the same time it is strongly interlinked with other disciplines. In fact the division of chemistry into physical, inorganic, organic and bio is just one way of splicing and dicing the field, and as such is an arbitrary leftover of history. Some chemistry departments are now divided into synthetic, biological, materials, analytical and computational. One might equally divide the realm into micromolecular and macromolecular, not to mention that chemistry itself is becoming less distinguishable from biology and physics. Boundaries are always blurred and arbitrary. Just because something exists at the intersection of other domains, that by no means makes it less of an independent and more of a service science!

It is appropriate to end this section by returning to Staudinger. He was an organic chemist, but he found himself being trenchantly criticized by his colleagues after he published his so-called macromolecular concept. As is well known, he was advised as follows by a leading light: "Dear colleague, abandon your idea of large molecules, organic molecules with molecular weights 
exceeding 5000 do not exist. Purify your products such as rubber, they will crystallize and turn out to be low molecular weight compounds." ${ }^{[19]}$ Less polite colleagues referred to his pursuit of "Schmierenchemie". ${ }^{[19]}$ The end result of this wasted time looking into "grease chemistry" was the 1953 Nobel Prize! Of course, this recognition of macromolecular scientists was not a one-off by the Swedish Academy, being followed by Ziegler and Natta in 1963, by Flory in 1974, by de Gennes (in Physics) in 1991, and so on to the present day. One sees here indisputable recognition of an independent science of high intellectual order. Indeed, anyone who has delved into the books of Flory and de Gennes, in particular Statistical Mechanics of Chain Molecules and Scaling Concepts of Polymer Physics respectively, will have felt themselves to be in the hands of a genius taking them on a voyage of discovery through a distinct and awesome landscape. Furthermore, one notes the diverse backgrounds of these Nobel Prize winners: organic chemistry (HS), industrial chemistry and crystallography (GN), organometallic chemistry (KZ), physical chemistry (PF), physics (PGdG). Truly we are practitioners of an independent science, one with connections to physics and other fields of chemistry, but not in any sense just a service tool for them.

\section{In retrospect, were the key achievements of macromolecules predictable?}

Many of the key achievements in polymer science, as with most key achievements in all areas of science, may be regarded as predictable in hindsight. Indeed, “Isn’t that obvious?” is the hallmark of many a great discovery, from buoyancy through heliocentricity and gravity to condensation polymerization. Tell your students that discovery of nylon 6-6 synthesis was a giant conceptual leap forward, and watch them say “What's so hard about that?” But it took the genius of Carothers to think of reacting a diamine with a diacid, just as it took the genius of Archimedes, Galileo and Newton, respectively, in the other given examples. Further examples in chemistry 
specifically are Boyle’s law and Kekulé’s structure of benzene, while Michael Szwarc’s discovery of living polymerization in 1956 is equally a wonderful one. ${ }^{[20]}$ Indeed, Staudinger's macromolecular hypothesis seems exceedingly obvious in hindsight, but of course it wasn't at the time.

Some specific examples of predictable achievements in macromolecular science are use of polymers in lieu of other structural materials, discovery of hydrogel biopolymers, rational design of monomers to make them water soluble, and crosslinking of polymers - all these may be considered obvious discoveries. However, just because some achievements were obvious in hindsight, that does not make these discoveries any less heroic or impressive. Indeed, the Nobel Prizes that have been awarded in macromolecular science (see above) reflect the unique discoveries that have been made specifically for polymers, and we note that there have been none, for example, in metallurgy.

While there have been many important findings in polymer science, we will use the following key achievements to discuss the issue of predictability in more detail: (i) controlled polymerizations such as atom transfer radical polymerization (ATRP) and group transfer polymerization (GTP); (ii) stereochemical control, whether stereospecific olefin polymerization or helix control; and (iii) semiconducting polymers.

(i) Controlled polymerizations: One of the key polymerization reactions that has been developed over the past few decades is ATRP (Figure 5), which at last enabled Michael Szwarc's brilliant living-polymerization paradigm to be realized in radical polymerization. ${ }^{[20,21]}$ As Sawamoto has indicated in his publications, ${ }^{[22]}$ the original version of ATRP is based on the Kharasch reaction. This is a very convenient radical reaction that can be used for the construction of small-molecule ring systems. However, it had never been extended to controlled polymer 
synthesis until Matyjawsewski and Sawamoto did so in $1994 .{ }^{[23-25]}$ Minoura had reported on the effects of metals on radical polymerizations, ${ }^{[26,27]}$ which in hindsight can be taken as hints or clues toward the discovery of ATRP. However, the fact that this reaction could lead to controlled polymerization was not obvious.

Turning now to GTP, it can be understood to be an improved version of Mukaiyama's reaction. ${ }^{[28-30]}$ However, according to Dr Dotsevi Y. Sogah, who was a key researcher in the group at DuPont led by Webster that invented GTP, it works well only when dedicated catalysts, which were elaborated by the DuPont group, are used. Simple application of common Mukaiyama conditions never led to good GTP resulting in targeted molar mass and narrow dispersity. From this point of view, the invention of GTP was only hinted at by Mukaiyama and it was not predictable.

(ii) Stereochemical control in polymerization: Basic stereochemistry of small molecules, including the concepts of meso and racemic (racemo) units in addition to stereochemistry of short peptides (Fischer ${ }^{[31]}$ ) and sugars, had already been established or studied in depth by 1954, the year of Natta's iso-PP. ${ }^{[32]}$ However, there is a clear leap between Ziegler and Natta's findings about polymerizations and the preceding, small-molecule-oriented stereochemistry. Firstly, their work is about control of a pseudo-chirality center, which was not the central topic in small-molecule stereochemistry, where true chirality centers were mainly discussed in peptides and sugars. Second, stereochemistry of small molecules was studied mainly by polarimetry (if a compound was chiral and optically active) or by crystallography at that time. However, only XRD spectra of fibers or powder samples, in addition to "solubility" of polymers, were available for Natta to investigate the stereochemistry of his polymers. Obtaining stereochemical control of polymers and 
analyzing them required a leap of faith and a different set of tools than those that were used in small molecule studies.

As for helix control, it is the finding of stable polymer-chain helices in solution. The field was initiated by Okamoto (polymethacrylates ${ }^{[33-35]}$; Figure 6) and by Nolte and Drenth (polyisocyanides ${ }^{[36,37]}$ ). Of course proteins ${ }^{[38]}$ and DNA ${ }^{[39]}$ had earlier been found to possess helical conformation. However, what Okamoto, Nolte and Drenth found were completely artificial helical polymers in which only steric repulsion and not H-bonding helped the helix to be sustained in solution. Additionally, helicity is not controlled by centers of chirality but by the catalyst in the synthesis. At the time of their findings, no one had ever imagined that the concept of stable conformation could be applied to an artificial polymer having no centers of chirality.

(iii) Semiconducting polymers: Given that the delocalization of electrons in benzene was known, perhaps one could consider that the discovery of semiconducting polymers was obvious. However, the discovery by Heeger, MacDiarmid and Shirakawa that doped polyacetylene was conducting $^{[40]}$ was one that occurred because of miscommunication, misunderstanding and some amount of informed insight. ${ }^{[41]}$ Specifically, while polyacetylene was already known and theoretically considered to be conducting, the original form was an intractable black powder that could not be processed. However, a fortuitous mistake by a visiting researcher in Shirakawa's group led to the use of a thousand-fold excess of catalyst in the synthesis, which led to the formation of a silvery film. This film could then be exposed to bromine vapor, and the scientists discovered that the conductivity of the film was enhanced by a factor of 10 million. Without this fortuitous misunderstanding - using a molar rather than a millimolar amount of catalyst - we may never have developed what is now an extensive field of research! 
In all these examples one sees major discoveries in macromolecular science that can superficially be portrayed as predictable on the basis of preceding work in other areas of chemistry. But upon closer inspection all these discoveries turn out to be underpinned by a level of creative insight that is the preserve of only the most brilliant scientists.

\section{Where may the discipline go in the next 20-30 years? What are the open questions?}

The history of polymer science demonstrates that the discipline has benefitted from both incremental, "predictable" improvements as well as sudden, revolutionary advances. Let us address them each in turn.

The incremental improvements usually come about in response to pressure from the applications side. In this respect, the outlook for the next twenty years is positive. There are numerous areas where polymer-based materials are well on the way to providing solutions to help ameliorate some of today's most pressing problems, e.g. the climate emergency, ${ }^{[42]}$ sustainable development, ${ }^{[43]}$ and the preservation of the environment and human health. ${ }^{[44]}$ To be more specific, think of polymers for renewable energy production (e.g., photovoltaic ${ }^{[45]}$ or thermoelectric polymers), membranes ${ }^{[46]}$ for water desalinization, ${ }^{[47]}$ gas separation, batteries and fuel cells, new materials from natural sources, ${ }^{[48,49]}$ biocompatible polymers for controlled drug release ${ }^{[50]}$ cell culture, gene therapy or even artificial organs. The list could be much longer. A time frame of twenty years is long enough to allow much of this research to come to fruition with practical applications.

These advances in applied polymer research reflect a pattern in materials technology throughout the last century. Namely, from nylon for silk stockings to polypropylene for car parts, polymers have supplanted many traditional materials, thanks to advantages related to wide 
availability, low cost, light weight, durability, and the possibility to tailor properties through chemical modification. Any use of materials is fair game for polymers. Stimuli-responsive, selfassembled or self-healing polymers are examples of "smart" materials, ${ }^{[51-53]}$ going beyond the possibilities of traditional ones in approaching those of living matter. These "smart" materials could be enabled by dynamic covalent networks to provide adaptive/sensing materials, ${ }^{\left[{ }^{[5-58]}\right.}$ or vitrimers, ${ }^{[59,60]}$ an interesting new class of polymers developed inspired by work performed by Stadler on thermoplastic elastomers, ${ }^{[61]}$ which have properties of a thermoset but flow like viscoelastic liquids at higher temperatures. Furthermore, supramolecular polymers that are built on noncovalent interactions offer new opportunities in optoelectronic properties, self-healing materials, and bio-medical materials. ${ }^{[62,63]}$ It is with some interest and irony that we note that the naysayers of Staudinger's macromolecular concept believed that common polymers were what we now call supramolecular polymers.

One important goal for the next 20-30 years will be to make commodity materials such as polyolefins from renewable and sustainable sources. Equally important is to develop new commodity materials that are inherently sustainable and degradable. For example, can we develop catalysts for efficient conversion of $\mathrm{CO}_{2}$ and epoxides into useful polymers? Can we produce reversibly cross-linked elastomers, avoiding the problems associated with the recycling of car tyres? On a different note, can we get closer to the power and flexibility of natural macromolecules with synthetic polymers? Will we be able to design and make large, sequence-controlled polymers consistently, efficiently and on reasonable scales? More importantly, will they be useful, and will they teach us anything about the machinery of life?

An example of a specific goal for the next 20-30 years is better macromolecules for lithiumion rechargeable batteries. As is well known, modern society is greatly dependent on portable 
electronic devices such as smart-phones, laptops, electric vehicles (EVs), etc. In particular the demand on EVs equipped with self-contained batteries will explode in the $21^{\text {st }}$ century due to the imperative of reducing carbon footprints. ${ }^{[64-70]}$ Lithium is here to stay due to its superior potential for energy storage, apart from being light in weight, electropositive, non-toxic and broadly available. At the same time, the perils of current lithium-ion batteries are well publicized. Therefore solid polymer electrolytes (SPEs) have been studied to replace the flammable liquid electrolytes. This field began when Fenton et al. dissolved metal salts in poly(ethylene oxide) forming conductive solid solutions. ${ }^{[71]}$ SPEs have yet to meet the standard requirements of rechargeable batteries, e.g. the conductivity should be at least $10^{-3} \mathrm{~S} \mathrm{~cm}^{-1}$ at room temperature, and the lithium ion transference number should be sufficiently high. ${ }^{[72,73]}$ High ionic conductivity coexisting with high lithium ion transference number may lead to a reduction of polarization (resistance), and hence electrical performance can be enhanced. ${ }^{[74]}$ Various strategies for polymer hosts have been introduced to improve the electrical properties of the SPEs, e.g. polymerblends, ${ }^{[74-78]}$ addition of fillers (e.g. $\left.\mathrm{Al}_{2} \mathrm{O}_{3}, \mathrm{TiO}_{2}\right),{ }^{[72,73,79,80]}$ addition of plasticizers, ${ }^{[81-83]}$ tuning macromolecular architectures (e.g. block copolymers, ${ }^{[84-86]}$ graft copolymers, ${ }^{[87-89]}$ polymer networks ${ }^{[90-92]}$ ), or a combination of these strategies. ${ }^{[93-95]}$ Efficient energy storage is the prerequisite for the switch from fossil fuels to electrically-powered vehicles, and discovery of new anode materials, cathode materials and electrolytes is anticipated for sustainable battery technology.

As mentioned before, the properties of polymer materials are notoriously time dependent (viscoelasticity). On top of this they are history dependent. This means that the conditions of full thermal equilibrium are seldom satisfied. Polymers tend to become kinetically trapped in metastable states, characterized by different degrees of microphase separation, partial order, self- 
assembled morphologies or "quenched" degrees of freedom. This is not necessarily a bad thing, as long as we understand how to control it. State-of-the-art simulation methods, ${ }^{[96-98]}$ including both particle-based simulations (e.g., atomistic and coarse-grained molecular dynamics) and continuum-based simulations (e.g., self-consistent field and density functional theories), can now reproduce the main equilibrium properties of many polymer systems, such as polymer melts and block polymers. Nonetheless, the simulation of the kinetics of phase separation and self-assembly, and of the non-equilibrium properties of polymeric materials (e.g., under flow or mechanical deformation, temperature gradients, electric fields, etc.), is still challenging.

Modelling the interaction of polymers with other materials (e.g, inorganic surfaces, biological tissues, etc.) is also non-trivial. One could say that the experimental advances and application requirements keep setting the bar for theory and simulations at a higher level. Relying on sheer computer power will not be enough to keep up with the pace - new theoretical ideas and algorithms will be necessary. For example, we are seeing the emergence of "experimentally constrained" simulations, ${ }^{[99-101]}$ in which the information coming from experiments (e.g., X-ray scattering or NMR) is used to guide the evolution of the simulated system in directions which are consistent with those. We also mention the "inverse design" problem: given a set of desired material properties (e.g., glass transition temperature, morphology, optical absorption coefficient, etc.), is it possible to design a polymer sequence, or the composition of a polymer blend, so as to produce those characteristics? Machine learning and techniques for extracting useful information from "big data" have also entered the field of molecular simulation and may be expected to become pervasive in the next decade. ${ }^{[102]}$

Turning now to revolutionary advances, almost by definition they are unpredictable. We cannot say much about those, except that the history of science teaches us that they are more likely 
to come from fundamental, curiosity-driven research. One could argue that the first such advance in the field is the one which was its birth, namely Staudinger's macromolecular hypothesis in 1920 . The interplay of theoretical ideas and on-purpose designed experiments can be very fruitful, as demonstrated by the changes in our understanding of polymers brought about in the 1970s by de Gennes $^{[103]}$ and his school. This also exemplifies the power of an influential individual to transform a subject, after entering it sideways from another field.

For the reasons given above, polymer science will remain a healthy and vigorous research field, all the more so for being open and attractive to researchers from all disciplines, whether chemists, physicists, engineers, biologists, medical scientists, whatever. The Polymer Division of IUPAC can play an important role in this not only through its long-standing work on terminology, nomenclature and standardization, but also by facilitating cross-discipline exchanges while preserving the core of the subject.

IUPAC can also play a role in another important challenge for polymer science, which is to continue attracting young minds to its study. New generations are increasingly aware of and sensitive to environmental problems, exemplified by plastic waste in the ocean. There is a risk that a public aversion to polymers may turn young scientists away from the subject. Polymers are obviously a part of such problems, but the bigger part is played by human behavior - whether at the individual or at the societal level - as driven by prevailing economic paradigms. ${ }^{[104]}$ Since it is difficult to envisage a future world without plastics, it seems clear that polymer science should be part of the solution, as opposed to being a sidelined player. Communication and dissemination are and will always be essential. As polymer scientists, we should strive to convey the idea that, in addition to being useful, and despite its century-old history, ours is still a lively, useful and intellectually exciting research area. 


\section{Conclusion}

Polymers are different from other materials - in particular small-molecule materials - in that one can play with several "variables" - molecular weight, tacticity, composition, branching, etc. - in order to obtain a continuum of properties between two extremes. Take for example ethene and propene: they are different compounds, and there is nothing “in between”. Consider instead the corresponding polymers, polyethylene and polypropylene: they are also different, but one can have a continuum of polymers “in between”. Even more interesting: the copolymers "in between” can have very different properties from the two starting points, being elastomeric instead of semicrystalline. Furthermore, even homopolymers of each can be quite different, namely LDPE versus HDPE (with LLDPE “in between”), and atactic PP versus isotactic PP (and the additionally distinct syndiotactic PP). Furthermore still, even these types of homopolymer can have dialed-up properties, for example UHMWPE versus HDPE, or LDPE with different branch densities.

Outlined above is a degree of complexity that is bewildering to a chemist who works only with small molecules. Frankly it is a foreign landscape to such a chemist, even though the reactions involved are all familiar. Thus the polymers from the simple molecules ethylene and propylene provide potent examples of all the discussion points in this article. There were many surprises in the historical development of PE and PP, not least of all the accidental discovery of LDPE synthesis in the first place. That PE and PP have made hugely significant contributions to science/humankind is so obvious it hardly needs stating. As already mentioned, the intricate, diverse web of homopolymer and copolymer variants from these two monomers is cogent evidence of macromolecular science being a discipline in its own right. Furthermore, the key achievements leading to the sheer variety of these polymers were not at all predictable, as discussed in Subsection 
4 regarding isotactic PP. Finally, who doubts that PE and PP will play a key role in taking our discipline in new directions in the next 20-30 years? If nothing else the need to minimize the number of commodity polymers so that they can be recycled more efficiently guarantees that PE and PP use will increase and broaden in the years to come.

There is the pun-catchcry “Chemists have solutions!” Equally true is the derivative of this: "Polymer chemists have solutions!" For example, we long ago developed all manner of biodegradable polymers, but it has just required political and societal willpower for their uptake. The graph in Figure 2 is still going up and it is still diverging from that for steel. Not only are polymers here to stay, but they'll continue to usurp traditional materials by improving upon them. We celebrate that, just as we celebrate the centenary of Staudinger's seminal research paper, ${ }^{[1]}$ which continues to infuse us with the optimism and determination to find a solution to any problem, providing only that we are given the necessary resources - in this way we are all heirs of the great Hermann.

\section{Acknowledgements}

We thank our IUPAC colleague Prof. Ehud Keinan for the invitation to write this article. We acknowledge our IUPAC Polymer Division colleague Dr. Chris Fellows for lively discussion and for his brainstorming contributions.

\section{References}

[1] H. Staudinger, Berichte der Dtsch. Chem. 1920, 53, 1073.

[2] H. Frey, T. Johann, Polym. Chem. 2020, 11, 8.

[3] S. Pinker, "Steven Pinker: 'The way to deal with pollution is not to rail against 
consumption,"” can be found under www.theguardian.com/science/2018/feb/11/stevenpinker-enlightenment-now-interview-inequality-consumption-environment, n.d.

[4] R. “Dick” Jones, Chem. Int. 2017, 39, 4.

[5] A. D. Jenkins, P. Kratochvil, R. F. T. Stepto, U. W. Suter, Pure Appl. Chem. 1996, 68, 2287.

[6] C. M. Fellows, C. K. Luscombe, G. T. Russell, Chem. Int. 2017, 39, 12.

[7] C. K. Luscombe, Macromolecules 2019, 52, 9065.

[8] J. E. Brandenberger, Composite Cellulose Film., 1914, US1266766A.

[9] L. H. Baekeland, Method of Making Insoluble Products of Phenol and Formaldehyde., 1909, US942699A.

[10] W. H. Carothers, I. Williams, A. M. Collins, J. E. Kirby, J. Am. Chem. Soc. 1931, 53, 4203.

[11] W. H. Carothers, Linear Polyamides and Their Production, 1935, US2130523A.

[12] M. Demirors, in 100+ Years Plast. Leo Baekel. Beyond (Eds.: E.T. Strom, S.C. Rasmussens), 2011, pp. 115-145.

[13] K. Ziegler, E. Holzkamp, H. Breil, H. Martin, Angew. Chemie 1955, 67, 541.

[14] G. Natta, J. Polym. Sci. 1955, 16, 143.

[15] O. Wichterle, D. Lím, Nature 1960, 185, 117.

[16] W. Otto, L. Drahoslav, Process for Producing Shaped Articles from Three-Dimensional Hydrophilic High Polymers, 1956, US2976576A.

[17] B. Adhikari, S. Majumdar, Prog. Polym. Sci. 2004, 29, 699.

[18] V. Abetz, K. Kremer, M. Müller, G. Reiter, Macromol. Chem. Phys. 2019, 220, 1800334.

[19] R. Mülhaupt, Angew. Chemie Int. Ed. 2004, 43, 1054. 
[20] M. Szwarc, M. Levy, R. Milkovich, J. Am. Chem. Soc. 1956, 78, 2656.

[21] J. Smid, M. Van Beylen, T. E. Hogen-Esch, Prog. Polym. Sci. 2006, 31, 1041.

[22] M. Kamigaito, T. Ando, M. Sawamoto, Chem. Rev. 2001, 101, 3689.

[23] J.-S. Wang, K. Matyjaszewski, J. Am. Chem. Soc. 1995, 117, 5614.

[24] M. Kato, M. Kamigaito, M. Sawamoto, T. Higashimura, Macromolecules 1995, 28, 1721.

[25] K. Matyjaszewski, J. Xia, Chem. Rev. 2001, 101, 2921.

[26] M. Lee, Y. Ishida, Y. Minoura, J. Polym. Sci., Polym. Chem. Ed. 1982, 20, 457.

[27] Y. Minoura, M. Lee, Polym. Prepr., Am. Chem. Soc., Div. Polym. Chem. 1979, 20, 150.

[28] T. Mukaiyama, T. Izawa, K. Saigo, Chem. Lett. 1974, 3, 323.

[29] T. Mukaiyama, K. Narasaka, K. Banno, Chem. Lett. 1973, 2, 1011.

[30] T. Mukaiyama, K. Banno, K. Narasaka, J. Am. Chem. Soc. 1974, 96, 7503.

[31] E. Fischer, Berichte der Dtsch. Chem. Gesellschaft 1903, 36, 2982.

[32] P. J. T. Morris, Arnold and Mabel Beckman center for the history of chemistry (EtatsUnis), Polymer Pioneers : A Popular History of the Science and Technology of Large Molecules, Beckman Center For The History Of Chemistry, 1990.

[33] T. Nakano, Y. Okamoto, Chem. Rev. 2001, 101, 4013.

[34] Y. Okamoto, K. Suzuki, K. Ohta, K. Hatada, H. Yuki, J. Am. Chem. Soc. 1979, 101, 4763.

[35] T. Nakano, J. Chromatogr. A 2001, 906, 205.

[36] A. J. M. Van Beijnen, R. J. M. Nolte, W. Drenth, A. M. F. Hezemans, Tetrahedron 1976, 32, 2017.

[37] P. C. J. Kamer, R. J. M. Nolte, W. Drenth, J. Am. Chem. Soc. 1988, 110, 6818.

[38] L. Pauling, R. B. Corey, H. R. Branson, Proc. Natl. Acad. Sci. U. S. A. 1951, 37, 205.

[39] J. D. Watson, F. H. C. Crick, Nature 1953, 171, 737. 
[40] H. Shirakawa, E. J. Louis, A. G. MacDiarmid, C. K. Chiang, A. J. Heeger, J. Chem. Soc. Chem. Commun. 1977, 578.

[41] H. Shirakawa, A. McDiarmid, A. Heeger, Chem. Commun. 2003, 1.

[42] “IPCC - Intergovernmental Panel on Climate Change,” can be found under https://www.ipcc.ch/, n.d.

[43] "Home | Food and Agriculture Organization of the United Nations," can be found under http://www.fao.org/home/en/, n.d.

[44] “WHO | World Health Organization,” can be found under https://www.who.int/, n.d.

[45] G. Li, R. Zhu, Y. Yang, Nat. Photonics 2012, 6, 153.

[46] M. Ulbricht, Polymer (Guildf). 2006, 47, 2217.

[47] M. A. Shannon, P. W. Bohn, M. Elimelech, J. G. Georgiadis, B. J. Mariñas, A. M. Mayes, Nature 2008, 452, 301.

[48] Y. Zhu, C. Romain, C. K. Williams, Nature 2016, 540, 354.

[49] C. Williams, M. Hillmyer, Polym. Rev. 2008, 48, 1.

[50] N. A. Peppas, J. Z. Hilt, A. Khademhosseini, R. Langer, Adv. Mater. 2006, 18, 1345.

[51] P. J. Roth, A. B. Lowe, Polym. Chem. 2017, 8, 10.

[52] Y.-J. Kim, Y. T. Matsunaga, J. Mater. Chem. B 2017, 5, 4307.

[53] A. C. Hunter, S. M. Moghimi, Polym. Chem. 2017, 8, 41.

[54] J. M. Winne, L. Leibler, F. E. Du Prez, Polym. Chem. 2019, 10, 6091.

[55] R. J. Wojtecki, M. A. Meador, S. J. Rowan, Nat. Mater. 2011, 10, 14.

[56] N. Roy, B. Bruchmann, J.-M. Lehn, Chem. Soc. Rev. 2015, 44, 3786.

[57] M. A. C. Stuart, W. T. S. Huck, J. Genzer, M. Müller, C. Ober, M. Stamm, G. B. Sukhorukov, I. Szleifer, V. V. Tsukruk, M. Urban, F. Winnik, S. Zauscher, I. Luzinov, S. 
Minko, Nat. Mater. 2010, 9, 101.

[58] C. J. Kloxin, C. N. Bowman, Chem. Soc. Rev. 2013, 42, 7161.

[59] W. Denissen, J. M. Winne, F. E. Du Prez, Chem. Sci. 2016, 7, 30.

[60] D. Montarnal, M. Capelot, F. Tournilhac, L. Leibler, Science 2011, 334, 965.

[61] R. Stadler, L. de Lucca Freitas, Polym. Bull. 1986, 15, 173.

[62] L. Brunsveld, B. J. B. Folmer, E. W. Meijer, R. P. Sijbesma, Chem. Rev. 2001, 101, 4071.

[63] L. Yang, X. Tan, Z. Wang, X. Zhang, Chem. Rev. 2015, 115, 7196.

[64] G. Zubi, R. Dufo-López, M. Carvalho, G. Pasaoglu, Renew. Sustain. Energy Rev. 2018, 89, 292.

[65] D. Zhou, D. Shanmukaraj, A. Tkacheva, M. Armand, G. Wang, Chem 2019, 5, 2326.

[66] Y. Ding, Z. P. Cano, A. Yu, J. Lu, Z. Chen, Electrochem. Energy Rev. 2019, 2, 1.

[67] J. B. Goodenough, K.-S. Park, J. Am. Chem. Soc. 2013, 135, 1167.

[68] B. Huang, Z. Pan, X. Su, L. An, J. Power Sources 2018, 399, 274.

[69] T. Kim, W. Song, D.-Y. Son, L. K. Ono, Y. Qi, J. Mater. Chem. A 2019, 7, 2942.

[70] Y. Koshtyal, M. Maximov, D. Nazarov, A. Rumyantsev, Q. Sheng Wang, SHS Web Conf. 2018, 44, 00048.

[71] D. E. Fenton, J. M. Parker, P. V. Wright, Polymer (Guildf). 1973, 14, 589.

[72] W. Wieczorek, K. Such, H. Wyciślik, J. Płocharski, Solid State Ionics 1989, 36, 255.

[73] P. Yao, H. Yu, Z. Ding, Y. Liu, J. Lu, M. Lavorgna, J. Wu, X. Liu, Front. Chem. 2019, 7, 522.

[74] S. I. A. Halim, C. H. Chan, T. Winie, Macromol. Symp. 2017, 371, 114.

[75] S. R. A. Karim, L. H. Sim, C. H. Chan, H. Ramli, Macromol. Symp. 2015, 354, 374.

[76] F. Deng, X. Wang, D. He, J. Hu, C. Gong, Y. S. Ye, X. Xie, Z. Xue, J. Memb. Sci. 2015, 
491, 82.

[77] Y.-J. Li, C.-Y. Fan, J.-P. Zhang, X.-L. Wu, Dalt. Trans. 2018, 47, 14932.

[78] M. S. Khan, R. Gul, M. S. Wahid, J. Polym. Eng. 2013, 33, 633.

[79] S. Jayanthi, K. Kulasekarapandian, A. Arulsankar, K. Sankaranarayanan, B. Sundaresan, J. Compos. Mater. 2015, 49, 1035.

[80] C. Tang, K. Hackenberg, Q. Fu, P. M. Ajayan, H. Ardebili, Nano Lett. 2012, 12, 1152.

[81] P. Prabakaran, R. P. Manimuthu, S. Gurusamy, E. Sebasthiyan, Chinese J. Polym. Sci. 2017, 35, 407.

[82] A. Mejía, S. Devaraj, J. Guzmán, J. M. Lopez del Amo, N. García, T. Rojo, M. Armand, P. Tiemblo, J. Power Sources 2016, 306, 772.

[83] X. Qian, N. Gu, Z. Cheng, X. Yang, E. Wang, S. Dong, Mater. Chem. Phys. 2002, 74, 98.

[84] A. Pelz, T. S. Dörr, P. Zhang, P. W. de Oliveira, M. Winter, H.-D. Wiemhöfer, T. Kraus, Chem. Mater. 2019, 31, 277.

[85] D. Devaux, D. Glé, T. N. T. Phan, D. Gigmes, E. Giroud, M. Deschamps, R. Denoyel, R. Bouchet, Chem. Mater. 2015, 27, 4682.

[86] W.-S. Young, W.-F. Kuan, T. H. Epps, J. Polym. Sci. Part B Polym. Phys. 2014, 52, 1.

[87] H. Aydın, A. Bozkurt, J. Mater. Res. 2014, 29, 625.

[88] D. R. Sadoway, J. Power Sources 2004, 129, 1.

[89] P. E. Trapa, Y.-Y. Won, S. C. Mui, E. A. Olivetti, B. Huang, D. R. Sadoway, A. M. Mayes, S. Dallek, J. Electrochem. Soc. 2005, 152, A1.

[90] X. Hou, K. S. Siow, Polymer (Guildf). 2001, 42, 4181.

[91] H.-S. Kim, J.-H. Shin, S.-I. Moon, S.-P. Kim, Electrochim. Acta 2003, 48, 1573.

[92] L. J. Goujon, A. Khaldi, A. Maziz, C. Plesse, G. T. M. Nguyen, P.-H. Aubert, F. Vidal, C. 
Chevrot, D. Teyssié, Macromolecules 2011, 44, 9683.

[93] D. Li, C. Pu Hu, S. Kang Ying, Solid State Ionics 1994, 72, 172.

[94] A. J. Nagajothi, R. Kannan, S. Rajashabala, Mater. Res. Innov. 2018, 22, 226.

[95] R. J. Sengwa, P. Dhatarwal, S. Choudhary, Curr. Appl. Phys. 2015, 15, 135.

[96] T. E. Gartner, A. Jayaraman, Macromolecules 2019, 52, 755.

[97] J. Wu, Z. Li, Annu. Rev. Phys. Chem. 2007, 58, 85.

[98] C. Peter, K. Kremer, Soft Matter 2009, 5, 4357.

[99] W. Boomsma, J. Ferkinghoff-Borg, K. Lindorff-Larsen, PLoS Comput. Biol. 2014, 10, e1003406.

[100] G. C. Rutledge, Phys. Rev. E 2001, 63, 021111.

[101] S. J. L. Billinge, I. Levin, Science (80-. ). 2007, 316, 561.

[102] B. Sanchez-Lengeling, A. Aspuru-Guzik, Science 2018, 361, 360.

[103] P.-G. de. Gennes, Scaling Concepts in Polymer Physics, Cornell University Press, 1979.

[104] N. Klein, This Changes Everything: Capitalism vs. the Climate, Simon \& Schuster, 2015.

[105] D. Huang, D. Wu, Mater. Sci. Eng. C 2018, 90, 713.

[106] “World Plastics Production 1950-2015,” can be found under https://committee.iso.org/files/live/sites/tc61/files/The Plastic Industry Berlin Aug 2016 Copy.pdf, n.d.

\section{Figure captions}

Figure 1 Eras in the evolution of polymer usage: (A) Natural polymers; (B) Tough synthetic polymers replacing other materials; (C) Applications where macromolecules are indispensable, 
including light composite materials, hydrogel biomaterials, and drug delivery systems. (Bottom right image reprinted from Materials Science and Engineering: C, Vol 90, Da Huang and Decheng Wu, Biodegradable dendrimers for drug delivery, 713, ${ }^{[105]}$ Copyright 2018 with permission from Elsevier.)

Figure 2 Living in the Age of Plastics: world-wide production of polymers (compounds composed of macromolecules) vs. steel. ${ }^{[106]}$

Figure 3. A selection of daily life objects made from macromolecules: (left to right by rows from top to bottom): blood storage bag from PVC; high-tech sports equipment and shoes; kitchen appliance; electronic devices, including mobile phone and solar cell; paint; car interior; pipes; plastic window frame; toys; eyewear; hygiene; packaging.

Figure 4. Macromolecular science is interlinked with not only the other disciplines inside chemistry, but also with major disciplines outside chemistry, most notably physics, biochemistry and biology. (Note that this schematic reflects the relationships of macromolecular science only. For example, it does not show that inorganic chemistry overlaps with biology.)

Figure 5. Generic scheme representing ATRP.

Figure 6. Stable helical conformation of a polymethacrylate. (Reprinted with permission from Chem. Rev. 2001, 101, 4013. ${ }^{[35]}$ Copyright 2001 American Chemical Society.)

\section{TOC GRAPHIC}




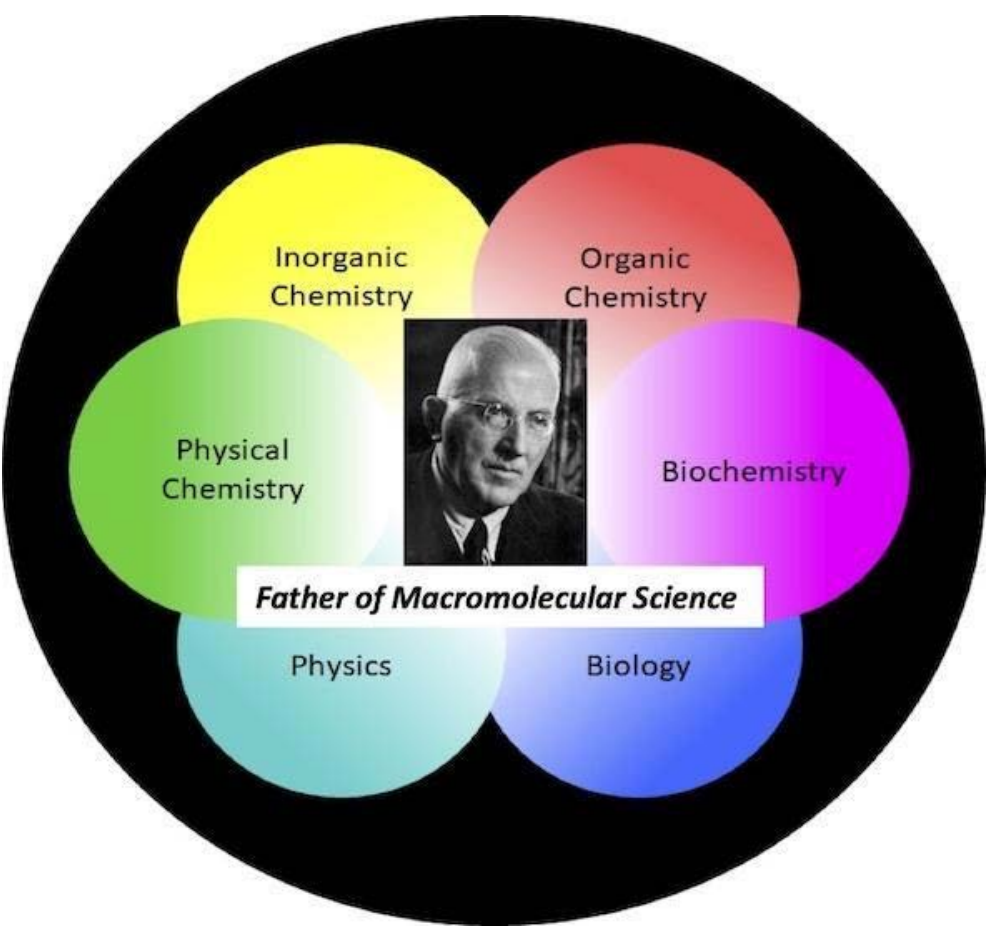

